Espaço Aberto | Open Space

\title{
O Museu Nacional: ciência e educação numa história institucional brasileira
}

The Museu Nacional (Rio de Janeiro): science and education in the history of a Brazilian institution

Luiz Fernando Dias Duarte*

* Museu Nacional, Universidade Federal do Rio de Janeiro - Rio de Janeiro, RJ, Brasil Ifdduarte@uol.com.br

https://orcid.org/0000-0001-7610-1527 


\title{
Resumo
}

Trata-se de abordar a "ilusão biográfica" institucional do Museu Nacional no momento da comemoração de seu bicentenário, do ponto de vista de um insider não historiador. Busca-se modelizar os ritmos de continuidade e descontinuidade dos sucessivos projetos institucionais vigentes ao longo dessa história, concentrando a atenção em alguns momentos de afirmação identitária mais nítida, num contexto geral sempre muito complexo, dependente e mutante. O contraste entre os momentos de apogeu que se espraiam entre o final do século XIX e a primeira metade do século XX e a relativa estagnação das primeiras décadas da segunda metade (em parte decorrente da incorporação efetiva à UFRJ) permitirá compreender a mudança representada pela conjugação da pesquisa à pós-graduação no último quartel do século, abrindo a fértil era em que ainda agora vive a instituição, em sua dimensão mais propriamente científica - apesar do desastre de 2018.

Palavras-chave: museu; ciência; educação; história.

\begin{abstract}
In the moment when the Brazilian National Museum commemorates its bicentennial, it is appropriate to tackle its institutional "biographic illusion", from the point of view of an insider who is not a professional historian. The analysis concentrates in the rhythms of continuity and discontinuity of the successive institutional projects, focusing in some especial periods when a clearer identity came to the fore, in a permanently complex, dependent and mutant context. The contrast between the rich period spawning from the end of the 19th century through the first half of the 20th and the relatively stagnant first decades of the second half (partly due to the actual incorporation to the University) will allow to understand the deep change triggered by the union between research and graduate studies programs characteristic of the last quarter of the century; a process that is still flourishing in the institution, in its most explicitly scientific dimension - in spite of the 2018 disastrous event.
\end{abstract}

Keywords: museum; science; education; history. 


\section{Introdução}

Não é sem um certo mal-estar que enceto a tarefa de lidar com a história institucional do Museu Nacional no momento em que a maior parte de seu patrimônio histórico, de seus tesouros culturais e científicos e da sua memória institucional se perdeu, nas chamas do incêndio de 2 de setembro de 2018. É claro, porém, que, nesse contexto desastroso, tanto mais oportuna - e mesmo imperativa - se torna a tarefa de evocar e tornar pública a história bissecular da instituição.

A catástrofe sobreveio em um momento de grande otimismo e entusiasmo. No dia 6 de junho tinha tido lugar a cerimônia comemorativa oficial dos 200 Anos, com a inauguração de uma bela exposição sobre os corais da costa brasileira e a assinatura de um generoso contrato de apoio institucional com o BNDES, que - ironicamente - previa a concepção e a instalação de um sistema de prevenção de incêndio, entre outras iniciativas de expansão e recuperação do patrimônio da casa.

A tristeza não fez arrefecer, no entanto, o entusiasmo. O corpo vivo da instituição vem se desdobrando em iniciativas múltiplas, buscando viabilizar a progressiva reconstrução do Palácio de São Cristóvão e a recomposição das condições de trabalho das centenas de professores, técnicos, funcionários e alunos que perderam quase totalmente seus gabinetes, seus laboratórios, suas coleções e suas bibliotecas.

Este trabalho, já em sua concepção original, ${ }^{1}$ buscava compreender justamente como uma nova era de vitalidade tinha vindo aí prevalecer; fazendo com que o bicentenário não fosse uma vã efeméride a comemorar, mas a justa consideração de um trajeto coroado de sucesso e prenhe de novas perspectivas, após tantos altos e baixos desnorteantes.

Evocar a noção de "ilusão biográfica”, do acervo analítico de Pierre Bourdieu, para a compreensão de uma história "institucional" visava sublinhar como a figura hodierna do "Museu Nacional", em toda sua complexidade, podia ou não ser considerada em continuidade com os sucessivos "Museus Nacionais" que se constituíram ao longo do tempo, ao sabor de mudanças políticas externas e

1 Baseia-se nas notas de palestra que proferi no Museu de Astronomia e Ciências Afins/Mast (CNPq), em 25 de maio de 2018, sobre "O bicentenário do Museu Nacional. Ciência e educação numa história institucional brasileira". 
internas, de mudanças epistemológicas e acadêmicas, de mudanças na concepção do que fosse a relação entre a ciência, a cultura e a nação brasileira.

Minha competência para esse trabalho não decorre de uma formação de historiador, mas apenas da condição de antropólogo ao serviço da casa em múltiplas funções políticas e administrativas, além das científicas e acadêmicas que lhe competiam de ofício. A experiência de diretor da instituição entre 1998 e 2001, em especial, tornou-me agudamente atento aos sinais do passado nas circunstâncias do presente, o que só se exacerbou em minha mais recente condição de presidente e vice-presidente (em sucessivos mandatos) da Associação Amigos do Museu Nacional (SAMN) e de coordenador da Comissão Comemorativa dos 200 Anos. Essa atenção me permitiu conhecer muito da bibliografia pertinente à matéria, ainda que não de todas as obras mais recentes, que se avolumam em ritmo acelerado, sob a forma de trabalhos de tese (nem todos publicados) (Agostinho, 2014; Aranha Filho, 2011; Keuller, 2008; Martins, 2015; Nascimento, 2009; Pereira, 2010; Rangel, 2007; Santos, 2011; Sily, 2012; Turin, 2009; Veloso, 2013) ou de investimentos de historiadores especializados em ciência e museus (Dantas, 2001a, 2007a, 2007b, 2008a, 2008b, 2015; Dantas; Dos Santos, 2011a, 2011b, 2012; Domingues, 2010; Duarte, R., 2010; Gualtieri, 2008; Heizer, 2008; 2010; Lima; Sá, 2008; Podgorny; Lopes, 2016; Ribeiro, 2010; Schwarcz; Dantas, 2008; Soares, 2015; Souza et al., 2009; Turin, 2011).

Deve ser evidente ainda que o esclarecimento de uma acidentada trajetória institucional de dois séculos não pode caber num único artigo senão sob forma drasticamente compactada, com a economia de muita informação relevante que a bibliografia aportada em apoio poderá suprir aos interessados mais profissionais.

\section{As primeiras décadas do século XIX}

Como se pode imaginar, o Museu Real criado por D. João VI no Rio de Janeiro em 1818 era bastante improvisado, contendo coleções heteróclitas de ciência, arte e indústria - mais propriamente um "gabinete de curiosidades" público do que o "museu de história natural" em que se transformaria paulatinamente, no momento e ritmo mesmo em que idêntico processo se consolidava nas metrópoles avançadas. Era, ainda assim, um elemento importante da vida cultural 
da capital do novo império, atraindo a curiosidade dos nativos e dos visitantes ilustrados que se beneficiavam da ainda recente abertura dos portos "às nações amigas". Foi abrigado num palacete do centro da cidade, onde permaneceria até o final do século, beneficiando-se supostamente de algumas sobras das coleções da extinta Casa dos Pássaros e, sucessivamente, de crescentes acréscimos de variada ordem. Abrigaria também a famosa Coleção Werner, de mineralogia, adquirida originalmente pela casa real portuguesa para o ensino na metrópole.

As exposições foram abertas ao público ainda antes da independência e permaneceram assim, intermitentemente, ao longo desse século formador. Em 1831 foi fundado o seu Herbário e em 1865, a sua Biblioteca. Nessas primeiras décadas o museu constituiu uma espécie de viveiro cultural, beneficiário como foi sendo, crescentemente, das atenções letradas do segundo imperador. O Instituto Histórico e Geográfico Brasileiro (IHGB), a Sociedade Auxiliadora da Indústria Nacional, a Sociedade Vellosiana de Ciências Naturais foram criadas no âmbito do museu, para se autonomizar aos poucos.

As coleções propriamente científicas se beneficiaram das numerosas expedições científicas do período, sobretudo da Comissão Científica de Exploração (conhecida como "Comissão das Borboletas"), realizada em 1859, cujo rico acervo de peças, textos e ilustrações veio para o Museu Nacional. Doações da família imperial foram recorrentes, destacando-se a coleção de testemunhos da cultura egípcia clássica e a coleção de materiais etruscos e greco-romanos aportados ao Brasil por vontade da imperatriz Teresa Cristina.

A partir de 1861, com a responsabilidade de participação na primeira Exposição Nacional, o museu passou a ter intenso protagonismo nas representações do país nas Exposições Internacionais, essa vitrine essencial das transformações aceleradas na "civilização" das nações modernas (Dantas, 2015; Dantas; Dos Santos, 2011a; Kullmann Junior, 2001; Nascimento, 2009; Neves, 1986; Pesavento, 1997; Sily, 2012).

Em todo esse período o museu serviu como uma vitrine instável do Brasil para os visitantes estrangeiros e da "civilização" para os visitantes locais. Os primeiros se ressentiam da pouca representatividade da informação disponível sobre a natureza local; mas, quando se tratava de cientistas participantes de expedições, buscavam evitar o depósito no museu local de parte das coleções amealhadas. Para a administração imperial o Museu Nacional era, de qualquer modo, um aparelho essencial para a construção de uma imagem nacional, 
envolvendo o patrimônio natural local no diálogo com as recentes configurações dos Estados-nação modernos (Duarte, L., 2005).

\section{A geração de Ladislau Netto}

O botânico Ladislau Netto, ao retornar de sua formação europeia, entrou para os quadros do Museu Nacional em 1866. Em 1870, já como diretor adjunto, dava início a uma era de grandes transformações no desenho geral da instituição, afinadas com as transformações mais gerais na configuração política e cultural da nação, a partir do fim da Guerra do Paraguai e das primeiras manifestações de um projeto republicano. A administração de Ladislau Netto (entre 1874 e 1893) foi considerada, na primeira metade do século XX, como "a idade de ouro do Museu Nacional" (Sily, 2012, p. 62)

Esse período coincide também com grandes transformações no campo científico internacional e com uma renovação generalizada do papel dos museus de história natural na promoção das identidades nacionais e da popularização e promoção da ciência.

A criação, em 1876, da revista Archivos do Museu Nacional, o primeiro periódico científico do país (ainda em circulação, embora intermitente), permitia ao museu a inserção nas aceleradas redes de circulação internacional da ciência, por meio da permuta entre bibliotecas de museus e demais centros de pesquisa. ${ }^{2}$

Entre 1874 e 1876 o museu instituiu um sistema de palestras públicas e de cursos livres, abrindo o leque de acesso ao conhecimento ali cultivado e divulgado - cabendo sem dúvida lembrar que não havia universidades no país, mas apenas as formações eclesiásticas e militares e as faculdades profissionais distribuídas pelo Recife, Salvador, Rio de Janeiro e São Paulo. Ladislau Netto (1870) inovou também ao publicar suas Investigações historicas e scientificas sobre 0 Museu Imperial e Nacional do Rio de Janeiro, em 1870; uma primeira tentativa autorreflexiva de abarcar o sentido geral da instituição, já cinquentenária.

Em 1880 foi criado o Laboratório de Fisiologia Experimental, acompanhando tendências internacionais de ponta e tornando a atividade biológica

2 Na lista dos membros correspondentes constante do seu primeiro número encontram-se os nomes prestigiosos de Ch. Darwin e J. L. A. de Quatrefages. 
do museu mais abrangente e atualizada. Foi dirigido por João Batista de Lacerda e Louis Couty, embora também interessasse ao próprio Ladislau Netto. ${ }^{3}$

As teorias sobre a evolução social e natural se intensificavam nessa segunda metade do século, sacudidas pelas propostas de Ch. Darwin. As hipóteses degeneracionistas se bifurcavam entre as que, num registro mais arcaico, postulavam um declínio passado da humanidade, manifesto nas condições de vida dos povos "primitivos", e aquelas outras, mais "modernas", que pregavam o declínio das pessoas e povos afetados pela miscigenação com raças mais "atrasadas" ou "degeneradas". A antropologia física, em diálogo com a psiquiatria, a criminologia, o direito penal, encontrava seu período de fastígio no museu, como em toda a comunidade científica internacional. Ladislau Netto foi um entusiasta das teorias da evolução natural e da redução naturalística de uma antropologia comparada. Foi nesse espírito de "fisiologista" que fomentou as extensas atividades de coleta antropológica do museu, de modo a organizar a Exposição Antropológica de 1882, de grande impacto público. Se, por um lado, a presença de artefatos indígenas de múltipla procedência e de representantes vivos de duas etnias específicas visavam confirmar a localização desses povos nas escalas da barbárie à civilização, por outro não deixaram de abrir uma janela de percepção da nação à dignidade de populações que não tinham servido até então senão como presa da catequese e da colonização.

Os trabalhos de campo de Netto levaram-no a perceber a importância e a propor - pioneiramente - um sistema de controle sobre os sítios arqueológicos da Ilha de Marajó e do Vale do Amazonas em 1888.

É possível que o impacto dos trabalhos de campo e o do sucesso da exposição de 1882 estejam entre os motivos para que, em 1888, se criasse a " 4 a Seção" da organização do museu, abrigando a Antropologia, a Etnologia e a Arqueologia. As ciências humanas passavam a ter doravante uma legitimidade maior do que as primeiras referências à arqueologia e aos "usos e costumes" (regulamento de 1842) ou do que o estatuto oficialmente periférico que a arqueologia, a etnologia (e a numismática) tinham merecido na década anterior (estatuto de 1876). É claro que, por antropologia, se entendia ainda sobretudo a antropologia física, de crescente importância no quadro das discussões sobre a raça e a nação.

3 Louis Couty, morto precocemente, escreveu uma interessante análise da composição social e racial do país, demonstrando que ele "não tinha povo", apenas escravos. 
João Batista de Lacerda, que veio a ser diretor entre 1895 e 1915, é o nome ainda mais conhecido desse período da passagem do século, graças ao seu protagonismo na discussão da polêmica tese do "embranquecimento progressivo" da população brasileira. Mas foi sobretudo conhecido à época como um fisiologista de renome internacional, que deu guarida às novas teorias de Pasteur.

Já em 1910 foram criados outros laboratórios - de química vegetal, de química geral, de entomologia agrícola, de fitopatologia, em função dos interesses do Ministério da Agricultura, Indústria e Comércio, a que o museu esteve vinculado por décadas, na passagem do século.

Por essa mesma época começaram a se formar e consolidar novas instituições científicas, a partilhar a responsabilidade concentrada no museu. O Museu Paraense, núcleo precursor do Museu Goeldi, foi fundado em 1855, o Museu Paulista, em 1893 e o Instituto Soroterápico, primeira configuração do que veio a ser a Fundação Oswaldo Cruz, em 1900. Os quadros técnicos dessas instituições frequentemente tinham tido formação no seio do Museu Nacional.

Em 1919, como sinal da crescente força das antropologias na casa, foi publicado o primeiro Guia das colleç̧ões de archeologia classica do Museu Nacional, elaborado pelo curador Alberto Childe (1919), dando seguimento a Anthropologia: guia das colleções, organizado por Roquette-Pinto (1915).

Bertha Lutz, um dos mais ilustres nomes do quadro do museu durante décadas, tanto como cientista quanto como intelectual pública, editou em 1919 um Indice dos Archivos do Museu Nacional (Lutz, 1919), que resumia um empreendimento editorial de grande impacto científico.

Em 1918, comemorou-se com entusiasmo o primeiro centenário da instituição. Ao lado dos luminares consagrados, apresentava-se, no relatório publicado em um número especial dos Archivos sobre a efeméride, uma palestra singela de um personagem que se tornaria cada vez mais importante para a casa: Edgar Roquette-Pinto (1919).

\section{A era de Roquette-Pinto}

Roquette-Pinto esteve ativo no Museu Nacional entre 1905 e 1935, quando dele se desvinculou para uma dedicação plena a suas iniciativas de difusão científica audiovisual. 
O início de sua carreira, para além da antropologia física da formação inicial, foi a excursão científica a Mato Grosso, em que, no ano de 1913, acompanhou a expedição do Marechal Rondon. Este último veio a ser um continuado companheiro do museu, que acolheu muitos de seus materiais etnológicos.

A era de Roquette-Pinto se caracterizou sobretudo pela dedicação à função educativa do museu, em um contexto nacional de grande exaltação das possibilidades de civilização pelo acesso ao conhecimento, exorcizando os vaticínios degeneracionistas que rondavam a nação desde o século XIX. Em 1927 foi por ele criado o Serviço de Assistência ao Ensino de História Natural do Museu Nacional (SAE), ainda hoje pujante, apesar de um eclipse na gestão de Heloisa Alberto Torres. Roquette-Pinto fundou ainda a Revista Nacional de Educação, que circulou entre 1932 e 1934, com grande tiragem, forte apoio oficial e grandes expectativas de contribuição à generalização do conhecimento na população nacional.

O Museu Nacional se notabilizou nesse período pela produção de quadros murais e coleções didáticas nas áreas de conhecimento aí cultivadas, para uso nos estabelecimentos de ensino de todo o país, como parte do trabalho de sua SAE.

Ainda nesse registro da educação científica, em 1923 o museu participou, por alguns de seus pesquisadores, da fundação da Academia Brasileira de Ciências, e, em 1924, da fundação da Associação Brasileira de Educação.

A segunda dimensão importante dessa era da história do museu foi a do desencadeamento e institucionalização da luta pela preservação natural e ambiental. Como relata um artigo importante sobre esse tópico:

No Brasil, esse tipo de perspectiva formou-se, sobretudo, no interior de certas instituições devotadas à ciência. A principal delas foi o Museu Nacional do Rio de Janeiro. Ao realizar pesquisas nos campos da história natural, da biologia e da antropologia, os cientistas e professores dessa instituição logo despertaram para o problema da destruição do patrimônio natural pelas ações humanas. Vários deles se dedicaram ao ativismo e à formulação de um pensamento focalizados na proteção da natureza. Entre eles podemos citar Cândido de Mello Leitão, Paulo Roquette-Pinto, Bertha Lutz, Heloísa Alberto Torres, Armando Magalhães Corrêa e Alberto José Sampaio. Frederico Carlos Hoehne, que teve em São Paulo atuação destacada em favor da proteção da natureza, também começou a sua carreira como botânico e taxonomista no Museu. (Franco; Drummond, 2005, p. 1034-1035). 
Pode-se lembrar inclusive que o Ministério da Educação e Saúde Pública, em 1932, solicitou ao museu a criação de um anteprojeto de regulamentação da caça no Brasil. Roquette-Pinto presidiu a comissão que levou a cabo a tarefa (Sily, 2012, p. 266).

A terceira frente pela qual se notabilizou o museu nessa era foi a da experimentação educacional com a radiodifusão e a cinematografia. Como lembra Sily (2012, p. 298):

durante o governo Vargas foram criados a primeira Comissão de Censura de Cinema em 1932, sendo Roquette-Pinto seu diretor e sua sede localizada no Museu Nacional e, em 1936, o Instituto Nacional de Cinema (INCE), órgão do Ministério de Educação e Saúde, tendo como ministro Gustavo Capanema.

Roquette-Pinto teve uma forte participação nos primórdios da produção cinematográfica brasileira, sendo considerado o autor do primeiro documentário antropológico nacional, filmado no começo de sua carreira, sobre os Nambiquara (Sily, 2012, p. 299).

Não há como aprofundar aqui o papel crucial de Roquette Pinto na consolidação da transição de uma antropologia dominada pela dimensão biológica para uma antropologia de tons culturalistas, coetânea dos trabalhos de Gilberto Freyre e de Arthur Ramos. O museu tinha as condições ideais para desenvolver uma antropologia de four fields local, o que quase chegou a se consolidar ao final da gestão de Heloisa Alberto Torres.

É um elemento significativo da vitalidade da instituição nessa era a criação da Sociedade dos Amigos do Museu Nacional (SAMN), em 1937, com uma hábil articulação entre cientistas da casa e alguns mecenas da elite carioca. Hoje ainda plenamente ativa, apesar de uma história de muitos sobressaltos, é a mais antiga associação de amigos de uma instituição cultural brasileira.

Uma longa viagem de trabalho realizada por Bertha Lutz aos Estados Unidos em 1933, de que resultou um precioso relatório (A função educativa dos museus norte-americanos) é outro elemento significativo dessa vitalidade, ainda que só tivesse vindo a ser publicado muito recentemente (Aranha Filho, 2011; Lutz, 2008; Sily, 2012).

O fim da era que coloquei sob a égide do nome de Roquette Pinto é marcado pelo longo reinado de sua sucessora Heloisa Alberto Torres, que iniciara 
a carreira na casa como sua estagiária na seção de antropologia. Foi nomeada diretora do Museu Nacional por Getúlio Vargas em 1938 e só terminou sua gestão em 1955, logo após o término da presidência eleita de Vargas.

Esse período, inseparável das características das sucessivas administrações Vargas, foi marcado pela presença ubíqua de "Dona Heloisa" nos órgãos de Estado, como a Comissão Nacional de Proteção dos Índios, o Conselho de Fiscalização das Expedições Científicas e Artísticas e o Serviço do Patrimônio Histórico e Artístico Nacional (de cujo Conselho Consultivo o museu continuou a participar até os anos 2000).

Seu discípulo Luiz de Castro Faria, muito importante no período subsequente, conservando esse comprometimento com a proteção do patrimônio, veio a ser o autor do projeto de lei para proteção das jazidas arqueológicas, que resultou na lei 3.924/1961 (Brasil, 1961).

Heloisa Alberto Torres garantiu uma consolidação da virada culturalista na antropologia do Museu Nacional, por seu papel eminente na Comissão das Expedições e por força da própria ação como diretora da casa. ${ }^{4} \mathrm{O}$ período corresponde ao ápice dessa primeira onda da antropologia culturalista brasileira, graças sobretudo à ação de Gilberto Freyre e Arthur Ramos, no Rio de Janeiro, e de Roger Bastide, em São Paulo.

O museu continuou sendo um viveiro de instituições culturais, disponibilizando coleções importantes para a fundação do Museu Histórico Nacional (1922) e do Museu Imperial (1940).

\section{A era da Universidade do Brasil/UFRJ}

Ainda durante a gestão de Heloisa Alberto Torres, o Museu Nacional foi por duas vezes incorporado à Universidade do Brasil: em 1937, quando esta foi criada, e em 1946, após seis anos de desincorporação. Tratava-se de um processo bastante formal, dado o caráter muito peculiar da nova universidade, um verdadeiro arquipélago de instituições tradicionais, muitas centenárias.

4 Seu longo contato com Franz Boas teria facilitado, por exemplo, a ida de Eduardo Galvão para sua formação antropológica na Columbia University (Souza Lima, 2000, p. 396). 
Em 1947 teve início um paulatino processo de reabertura das exposições, longamente fechadas nos anos anteriores, que só se completou na década de 1960.

O museu, por sua preeminência na área, abrigou a Primeira Reunião Brasileira de Antropologia no ano de 1953, quando se decidiu fundar a associação da área, finalmente concretizada na reunião seguinte, em Salvador. Em 1957 o museu sediou a IX Reunião Anual da Sociedade Brasileira para o Progresso da Ciência (SBPC) e em 1960, o I Congresso Nacional de Zoologia.

Em 1960 foi desencadeado o movimento da Reforma Universitária da Universidade do Brasil, de cuja comissão participou Luiz de Castro Faria, diretor da casa entre 1964 e 1967. Esse movimento foi o aguilhão de uma reforma mais geral de toda a universidade brasileira, progressivamente consolidada. Embora a reforma só fosse sancionada oficialmente em 1968, seus princípios já estavam em ação na universidade - não sem conflitos - no afastamento do regime da cátedra e na adaptação ao regime de indissociabilidade entre pesquisa, ensino e extensão, por exemplo.

Nesse mesmo ano de 1960, o antropólogo Roberto Cardoso de Oliveira, que vinha de uma atuação no Museu do Índio e no Serviço de Proteção ao Índio (SPI) junto com Darcy Ribeiro e Eduardo Galvão, dava início, junto com Luiz de Castro Faria, aos cursos de especialização em antropologia do Museu Nacional, que se estenderam até a criação, em 1968, do Programa de Pós-Graduação em Antropologia Social (PPGAS), com um curso de mestrado. O programa era pioneiro na organização de um curso de pós-graduação nessa área nos moldes "modernos" propugnados pelo Conselho Federal de Educação por meio de um famoso parecer de Newton Sucupira (parecer 977/1965) (Garcia Junior, 2009). Era também pioneiro na abertura às novas correntes de prestígio na antropologia internacional: a antropologia social britânica e - logo depois - a sociologia crítica francesa, o estruturalismo e o interacionismo simbólico.

As iniciativas de renovação da atividade universitária brasileira já vinham sendo sustentadas pela Fundação Fulbright, e passaram a receber, nos anos 1960, também o influxo dos recursos da Fundação Ford. Entre seus beneficiários na Universidade do Brasil, encontrava-se o Programa de Antropologia Social, favorecendo o desenvolvimento de suas linhas de pesquisa de campo e sua rápida consolidação acadêmica.

A dissolução da antiga Faculdade Nacional de Filosofia da Universidade do Brasil e sua distribuição em uma série de novas faculdades e institutos serviu 
para reforçar os grupos dinâmicos nas ciências envolvidas, exigindo do Museu Nacional uma nova interlocução - nem sempre amistosa - com os recentes Institutos de Biologia, de Geociências e de Filosofia e Ciências Sociais, assim como com a recente Faculdade de Letras.

No período que se seguiu à saída de Heloisa Alberto Torres da direção da casa, a ciência hegemônica no museu era a zoologia, que veio inclusive, pela importância de suas coleções e pelo alentado número de pesquisadores, a se dividir entre os departamentos de Vertebrados, Invertebrados e Entomologia. Dentre os cinco diretores que se seguiram a Dona Heloisa até meados dos anos 1970 apenas Luiz de Castro Faria não era zoólogo. O Programa de Pós-Graduação em Zoologia foi implantado em 1972, em parceria com as áreas correspondentes do Instituto de Biologia.

Diversos problemas afetaram a vitalidade do Museu Nacional nesse período. Em 1969, uma malfadada iniciativa do governo militar, suscitada pelo interesse pessoal de uma influente pesquisadora do museu, conferiu por decreto a diversos professores a qualidade de professores titulares. Essa medida provocou grande mal-estar dentro e fora do museu, prejudicando a legitimidade deste junto à universidade.

Por outro lado, a biologia do museu enfrentava com dificuldades a transição da sistemática morfológica, a que se dedicava tradicionalmente, para os novos recursos da biologia molecular, fundamento do que se fazia nos setores de ponta da disciplina. A própria atividade da sistemática e da manutenção das coleções naturalistas passava por um período de desprestígio em face de tantos novos horizontes de pesquisa emergentes. Faltavam inclusive ao museu, nesse sentido - cruelmente -, os dispendiosos equipamentos necessários para esse novo horizonte. ${ }^{5}$

Diferentemente da antropologia, que lograra se implantar solidamente na casa, dois outros setores promissores dela se afastaram, depois de se desenvolverem pioneiramente no museu: o Programa de Ecologia, fundado por Fernando Segadas Viana no Departamento de Botânica, seguiu para o Instituto de Biologia, e o Programa de Linguística, fundado por Aryon Dall'Igna Rodrigues no Departamento de Antropologia, seguiu para a Faculdade de Letras.

5 O microscópio eletrônico de varredura, longamente ansiado, só veio a ser adquirido e instalado no museu em 2008. 
Não menos importante foi a crescente sensação de asfixia de que se ressentia o museu, obrigado a fazer conviver no Palácio de São Cristóvão coleções científicas sempre crescentes, laboratórios cada vez mais exigentes, serviços técnicos sofisticados, gabinetes de trabalho de um corpo docente em expansão, bibliotecas dinâmicas e um número crescente de programas de pós-graduação. ${ }^{6}$ Numerosas iniciativas de obtenção de prédios vizinhos para o deslocamento de suas atividades redundaram em fracasso, o que acabou forçando a instituição a lutar pela construção de novos prédios no seu entorno imediato ou na área de seu Horto Botânico.?

Apesar dessas dificuldades, que foram tornando a instituição apagada em relação às novas unidades de pesquisa universitária, o processo de reorganização imposto pela influência da pós-graduação na casa foi se afirmando, pouco a pouco, em todos os seus setores científicos.

A partir de 1994, sobretudo, grandes novas iniciativas foram afirmando um horizonte de renovação. O apoio da Fundação Herbert Levy foi fundamental para as iniciativas de reforma do Palácio de São Cristóvão, pela via da Lei Rouanet, que permitiram a recuperação da fachada principal e da quase totalidade dos telhados (com recursos da Petrobrás); assim como o apoio da Fundação Vitae foi essencial para a renovação das condições de guarda das coleções científicas e para a refundação do Laboratório de Conservação, Preservação e Restauração de Coleções, que se tinha arruinado ao longo da década anterior.

A criação do Projeto Memória do Paço de São Cristóvão e do MN permitiu uma revitalização do inestimável arquivo geral do museu. Em 2000 foi instalado o Escritório Técnico-Científico para as Novas Exposições do MN (ETC/ PNE), com recursos do CNPq e da UFRJ, que funcionaria até 2003, produzindo um programa integrado conceitual e físico para as futuras exposições permanentes do museu e para a habilitação do palácio a seu novo destino. O projeto

6 O programa de Botânica juntara-se aos de Antropologia Social e Zoologia em 1976 - e ainda viriam a ser criados, mais recentemente, os de Arqueologia, Linguística e Geociências.

7 O Anexo Alípio Miranda Ribeiro, justaposto ao palácio, foi construído em 1957. Diversos pequenos prédios dedicados à Botânica (inclusive à Ecologia) foram inaugurados no Horto Botânico em 1962. Em 1989 foi erigido o prédio-sede da biblioteca geral do museu, também no horto - a que se seguiram, na década seguinte, os prédios do Departamento de Vertebrados e do de Botânica. 
adjudicava a totalidade do palácio-sede às exposições e seus serviços associados, contando com a transferência para novos prédios de todas as demais atividades e acervos do museu. Nesse sentido, foi contratado ao arquiteto Glauco Campelo um projeto integrado de construções no Horto Botânico, que só veio a se concretizar, por falta de recursos, na primeira unidade prevista, a do Departamento de Botânica (com o seu precioso Herbário).

A partir de 1998 foi empreendida uma política de renovação e valorização das exposições permanentes, assim como foi intensificado o ritmo de montagem de exposições temporárias, algumas das quais mereceram excelente acolhida do público. Em 2001, por exemplo, foram reabertas as salas da exposição permanente de arqueologia (Egito, Culturas Mediterrâneas e Arqueologia Brasileira), com um elegante projeto do arquiteto Jorge Hue.

$\mathrm{O}$ acervo cultural e científico foi objeto de novas atenções do Iphan, com o tombamento do exemplar da Torá do imperador Pedro II e o projeto de tombamento das Coleções Imperiais remanescentes nas reservas técnicas e nas exposições.

A SAE não cessou de ampliar suas atividades, tornando-se um veículo essencial na atenção aos visitantes em geral, mas, mais particularmente, no atendimento às escolas e escolares, e em iniciativas de divulgação científica mais tópicas e dinâmicas.

\section{As perspectivas para $03^{\circ}$ século}

Estou convencido de que, no momento em que se comemorava o bicentenário do Museu Nacional, ele se encontrava em um estado vital mais intenso e orgânico do que em qualquer outra de suas eras precedentes. As comemorações dos 200 Anos, coroadas pela bela festa de 6 de junho de 2018, pareciam justas e auspiciosas.

Desde minha experiência como diretor, eu me tornara muito pessimista em relação ao destino do museu, particularmente por força da sua acachapante subordinação administrativa e financeira à UFRJ - uma universidade agigantada, em permanente crise financeira e pouco sensível à especificidade do museu. Ao final de minha gestão como diretor, cheguei a participar de uma comissão interministerial, cujas conclusões vieram a convergir com minha 
disposição original: a de transformar o Museu Nacional em uma Instituição Federal de Ensino Superior autônoma, dona de orçamento próprio. Dadas as dificuldades que esse objetivo tinha que enfrentar, interna e externamente, continuei a pelejar pela autonomização, mas por outro meio: o da revitalização e fortalecimento da Associação Amigos do Museu Nacional, hoje plenamente instrumentalizada para carrear os recursos externos necessários à reprodução e avanço da casa.

Os desafios continuavam (e continuam) muito grandes. Não é fácil conduzir os destinos de uma instituição pejada de tradição que não pode deixar de ser ágil na atualização científica; de uma instituição em que convivem numerosas disciplinas totalmente distintas, dotadas de dinamismos internos assíncronos; de um patrimônio histórico e cultural tão valioso quanto o Palácio de São Cristóvão e as memórias de um império ilustrado, entremeado com os testemunhos do desenvolvimento do saber científico e com as necessidades de divulgação e popularização da ciência.

Quando se discutia o projeto das futuras exposições permanentes do museu, eu e Jayme Aranha viemos a formular em umas poucas chaves um programa que nos permitiria encaminhar um desafio bem característico dessa instituição tão multifacetada (Duarte; Aranha Filho, 2003). Acho que essas chaves bem ilustram ainda nossos destinos - sobretudo agora que as condições de reprodução institucional foram convulsionadas pelo incêndio. Tratava-se de garantir que as exposições atendessem às demandas de "historicidade", de "universalismo" e de "síntese" características da vocação institucional. Mais instrumentalmente, previa-se uma ênfase concomitante na "profundidade temporal", na "diversidade" ou "pluralidade" ontológica (fosse ela biológica ou cultural), na dimensão permanente de "transformação" ou "mudança", ${ }^{8}$ e na "relacionalidade" instituinte e dinâmica (quer se tratasse também da natureza e da vida social). Em função das características do Palácio de São Cristóvão e das coleções buscar-se-ia respeitar os princípios museológicos tradicionais do "espírito do lugar" e da "magia da peça".

8 O que deveria implicar uma delicada atenção à "explosão epistemológica" e à "crise dos paradigmas" que caracterizam o campo intelectual e científico da passagem do século XX para o XXI. 
Neste momento, em que mal se pode entrever o término da reconstrução do palácio e de sua reocupação pelas exposições do museu, esses ideais podem parecer excessivamente abstratos. Têm, no entanto, a vantagem de sublinhar as características que devem ser preservadas na própria identidade da instituição, ameaçada pela perda da maior parte de seu inestimável patrimônio. Muita coisa há de mudar, mas não - espero - aqueles marcos abrangentes que devem continuar a nortear o futuro geral da casa.

No nível mais prático, as iniciativas de recuperação do museu concentram-se em duas frentes de trabalho: a da reconstrução do palácio e a da recomposição da vida acadêmica e científica regular da instituição. Por ora, as atividades se concentram no que sobrou fisicamente: o Anexo contíguo ao palácio e o conjunto de prédios construídos no Horto Botânico. Felizmente eles abrigam partes muito preciosas do acervo que se salvaram do desastre: a Biblioteca, os departamentos de Botânica e de Zoologia de Vertebrados, e outros pequenos núcleos da Arqueologia e da Zoologia de Invertebrados.

Há muitas fontes de recursos, de múltipla origem, já em uso ou em processo de viabilização, através da SAMN, da Universidade Federal do Rio de Janeiro ou de outros meios, que buscam atender às duas frentes de ação. Um ponto essencial da linha de recomposição é o da obtenção de uma nova área física de ocupação, contígua ao horto, suficientemente ampla para abrigar a série de edificações necessárias para a reinstalação de espaços de coleção, de laboratórios, de gabinetes, de escritórios administrativos e - inclusive - de montagem de exposições temporárias que possam manter ativa a imagem pública característica da casa, assim como o atendimento aos estudantes e às escolas.

Há uma firme e muito generalizada disposição de luta a impregnar todos nós, sobreviventes inquietos das esperanças, dos projetos e do desastre que tudo ameaçou. À notória impermanência intrínseca das coisas humanas, opomos a memória desses dois séculos de luta profícua, como uma "ilusão" benigna e propiciatória a nos iluminar neste terceiro centenário. 


\section{Referências}

AGOSTINHO, M. B. O Museu em revista: a produção, a circulação e a recepção da revista Arquivos do Museu Nacional (1876-1887). 2014. Dissertação (Mestrado em História) - Instituto de Ciências Humanas e Filosofia, Universidade Federal Fluminense, Niterói, 2014.

ARANHA FILHO, J. Guia da impermanência das exposições: uma investigação sobre transformações do Museu Nacional do Rio de Janeiro nos anos 1940. 2011. Tese (Doutorado em Antropologia) - Instituto de Filosofia e Ciências Sociais, Universidade Federal do Rio de Janeiro, 2011.

BRASIL. Presidência da República. Casa Civil. Subchefia para Assuntos Jurídicos. Lei $n^{0}$ 3.924, de 26 de julho de 1961. Dispõe sôbre os monumentos arqueológicos e pré-históricos. Brasília, 1961. Disponível em: http://www.planalto.gov.br/ccivil_03/ leis/1950-1969/L3924.htm. Acesso em: 1 nov. 2018.

CHILDE, A. Guia das collecções de archeologia classica. Rio de Janeiro: Imprensa Nacional, 1919.

DANTAS, R. M. M. C. Breve histórico do Palácio Imperial da Quinta da Boa Vista. In: GAZZANEO, L. M. C. (org.). A monarquia no Brasil: 1808-1889: reflexões sobre as artes e as ciências. Rio de Janeiro: Book Link, 2001. p. 260-264.

DANTAS, R. M. M. C. A Casa do Imperador: do Paço de São Cristóvão ao Museu Nacional. In: SISTEMA DE BIBLIOTECAS E INFORMAÇÃO (org.). A Universidade e os múltiplos olhares de si mesma. Rio de Janeiro: Walprint, 2007a. p. 173-190.

DANTAS, R. M. M. C. A Coleção Werner e a criação do Museu Real. In: GAZZANEO, M. L. (org.). 200 anos da chegada da Família Real Portuguesa ao Brasil. Rio de Janeiro: PROARQ/UFRJ, 2007b. p. 216-237.

DANTAS, R. M. M. C. Pedro II e a botânica. In: FILGUEIRAS, C. A. L. et al. (org.). Scientiarum historia. Rio de Janeiro: WalPrint, 2008a. v. 1, p. 403-415.

DANTAS, R. M. M. C. Quando um museu dá samba: a popularização do Museu Nacional da UFRJ no Carnaval carioca. In: OLIVEIRA, A. J. B. (org.). Universidade e lugares de memória. Rio de Janeiro: WalPrint, 2008b. p. 127-144.

DANTAS, R. M. M. C. Casa Inca ou Pavilhão da Amazônia?: a participação do Museu Nacional na Exposição Internacional Universal em 1889, de Paris. Riga: Novas Edições Acadêmicas, 2015.

DANTAS, R. M. M. C.; DOS SANTOS, N. P. O Museu Nacional na Exposição Universal de Paris em 1889. In: LOPES, M. M.; HEIZER, A. (org.). Colecionismos, práticas de campo e representações. Campina Grande: Editora da Universidade Estadual da Paraíba, 2011a. p. 227-238. 
DANTAS, R. M. M. C.; DOS SANTOS, N. P. Quando um botânico se envolve com a antropologia: reflexões sobre Ladislau Netto no Museu Nacional. Scientiarum Historia, v. 1, p. 143-150, 2011b.

DANTAS, R. M. M. C.; DOS SANTOS, N. P. O Museu Nacional entre acervos científicos: o Museu do Imperador na Exposição Antropológica Brasileira de 1882. Scientiarum Historia, v. 1, p. 1-7, 2012.

DOMINGUES, H. M. B. Heloisa Alberto Torres e o inquérito nacional sobre ciências naturais e antropológicas, 1946. Boletim do Museu Paraense Emílio Goeldi: Ciências Humanas, v. 5, n. 3, p. 625-643, 2010.

DUARTE, L. F. D. La nature nationale: entre l'universalité de la science et la particularité symbolique des nations. Civilisations, Bruxelles, v. 52, n. 2, p. 21-44, 2005.

DUARTE, L. F. D.; ARANHA FILHO, J. Um museu de história natural na encruzilhada: a fundamentação conceitual para uma nova exposição no Museu Nacional. In: BITTENCOURT, J. N.; BENCHETRIT, S. F.; TOSTES, V. L. B. (org.). História representada: o dilema dos museus. Rio de Janeiro: Museu Histórico Nacional, 2003. p. 197-218.

DUARTE, R. H. A biologia militante: o Museu Nacional, especialização científica, divulgação do conhecimento e práticas políticas no Brasil - 1926-1945. Belo Horizonte: Editora UFMG, 2010.

FRANCO, J. L. A.; DRUMMOND, J. A. Armando Magalhães Corrêa: gente e natureza de um sertão quase metropolitano. História, Ciências, Saúde - Manguinhos, Rio de Janeiro, v. 12, n. 3, p. 1033-1059, set./dez. 2005.

GARCIA JUNIOR, A. R. Fundamentos empíricos da razão antropológica: a criação do PPGAS e a seleção das espécies científicas. Mana, Rio de Janeiro, v. 15, n. 2, p. 411-447, 2009.

GUALTIERI, R. C. E. Evolucionismo no Brasil: ciência e educação nos museus 18701915. São Paulo: Editora Livraria da Física, 2008.

HEIZER, A. Entre mudanças e permanências, Le Brésil en 1889 e o Bolletim Comemorativo da Exposição Nacional de 1908. In: ALMEIDA, M.; VERGARA, M. de R. (org.). Ciência, história e historiografia. São Paulo: Via Lettera; Rio de Janeiro: Mast, 2008. p. 293-304.

HEIZER, A. Ciência, civilização e república nos trópicos. Rio de Janeiro: Access, 2010.

KEULLER, A. T. A. M. Os estudos físicos de antropologia no Museu Nacional do Rio de Janeiro: cientistas, objetos, ideias e instrumentos (1876-1939). 2008. Tese (Doutorado em História Social) - Faculdade de Filosofia, Letras e Ciências Humanas, Universidade de São Paulo, São Paulo, 2008. 
KULLMANN JUNIOR, M. As grandes festas pedagógicas: a educação brasileira e as exposições internacionais (1862-1922). Bragança Paulista: Editora da Universidade São Francisco, 2001.

LIMA, N. T.; SÁ, D. M. de (org.). Antropologia brasiliana: ciência e educação na obra de Edgar Roquette-Pinto. Belo Horizonte: Editora UFMG; Rio de Janeiro: Editora Fiocruz, 2008.

LUTZ, B. M. J. Indice dos Archivos do Museu Nacional, volumes I-XXII 1876-1919. Rio de Janeiro: Museu Nacional, 1919.

LUTZ, B. M. J. A função educativa dos museus. Rio de Janeiro: Museu Nacional; Niterói: Muiraquitã, 2008. p. 13-27. (Série Livros do Museu Nacional, v. 33).

MARTINS, W. W. A Coleção Japonesa do Museu Nacional. 2015. Monografia (Graduação em Museologia) - Escola de Museologia, Universidade Federal do Estado do Rio de Janeiro, Rio de Janeiro, 2015.

NASCIMENTO, F. R. A formação da coleção de indústria humana no Museu Nacional, século XIX. 2009. Tese (Doutorado em Antropologia Social) - Museu Nacional, Universidade Federal do Rio de Janeiro, Rio de Janeiro, 2009.

NETTO, L. Investigações historicas e scientificas sobre o Museu Imperial e Nacional do Rio de Janeiro: acompanhadas de uma breve noticia de suas collecções e publicadas por ordem do Ministerio da Agricultura. Rio de Janeiro: Instituto Philomatico, 1870.

NEVES, M. de S. As vitrines do progresso: o Brasil nas Exposições Internacionais. Rio de Janeiro: PUC-Rio: Finep: CNPq, 1986.

PEREIRA, M. R. N. Educação museal: entre dimensões e funções educativas: a trajetória da $5^{\text {a }}$ Seção de Assistência ao Ensino de História Natural do Museu Nacional. 2010. Dissertação (Mestrado em Museologia) - Escola de Museologia, Universidade Federal do Estado do Rio de Janeiro, Rio de Janeiro, 2010.

PESAVENTO, S. J. Exposições Universais: espetáculos da modernidade do século XIX. São Paulo: Hucitec, 1997.

PODGORNY, I.; LOPES, M. M. Filling in the picture: nineteenth-century museums in Spanish and Portuguese America. Museum History Journal, v. 9, n. 1, p. 3-12, 2016.

RANGEL, J. A. da S. A musealização da educação na antropologia de Edgard Roquette-Pinto no Museu Nacional (1905-1936). 2007. Tese (Doutorado em Educação) - Faculdade de Educação, Universidade de São Paulo, São Paulo, 2007. 
RIBEIRO, A. M. M. Uma mulher intelectual em tempos pioneiros: Heloisa Alberto Torres, nação e a formação das ciências sociais brasileiras. Boletín Onteaiken, n. 10, p. 79-92, nov. 2010.

ROQUETTE-PINTO, E. Anthropologia: guia das collecções. Rio de Janeiro: Typographia da Directoria Geral de Estatistica, 1915.

ROQUETTE-PINTO, E. O centenario do Museu Nacional. Archivos do Museu Nacional, Rio de Janeiro, v. 22, p. 27-30, 1919.

SANTOS, R. de C. M. No “Coração do Brasil”: Roquette Pinto e a Expedição à Serra do Norte (1912). 2011. Dissertação (Mestrado em Antropologia Social) - Museu Nacional, Universidade Federal do Rio de Janeiro, Rio de Janeiro, 2011.

SCHWARCZ, L. M.; DANTAS, R. M. O Museu do Imperador: quando colecionar é representar a nação. Revista do Instituto de Estudos Brasileiros, n. 46, p. 123-165, fev. 2008.

SILY, P. R. M. Casa de ciência, casa de educação: ações educativas do Museu Nacional (1818-1935). 2012. Tese (Doutorado em Educação) - Faculdade de Educação, Universidade do Estado do Rio de Janeiro, Rio de Janeiro, 2012.

SOARES, M. C. Collectionism and colonialism: the Africana Collection at Brazil's National Museum (Rio de Janeiro). In: ARAUJO, A. L. (ed.). African heritage and memories of slavery in Brazil and the South Atlantic world. New York: Cambria Press, 2015. p. 17-44.

SOUZA, V. S. et al. Arquivo de Antropologia Física do Museu Nacional: fontes para a história da eugenia no Brasil. História, Ciências, Saúde - Manguinhos, Rio de Janeiro, v. 16, n. 3, p.763-777, jul./set. 2009.

SOUZA LIMA, A. C. L'indigenisme au Brésil. Migration et réappropriations d'un savoir administratif. Revue de Synthèse, Paris, v. 121, n. 3-4, p. 381-410, 2000.

TURIN, R. Tempos cruzados: escrita etnográfica e tempo histórico no Brasil oitocentista. 2009. Tese (Doutorado em História) - Universidade Federal do Rio de Janeiro, Rio de Janeiro, 2009.

TURIN, R. “Tipos”, “primitivos”, “decadentes”: escrita etnográfica, secularização e tempo histórico no Museu Nacional. In: NEVES, L. M. B. P. et al. (org.). Estudos de historiografia brasileira. Rio de Janeiro: Editora FGV, 2011. p. 183-206.

VELOSO, C. Os curiosos da natureza: Freire Allemão e as práticas etnográficas no Brasil do século XIX. 2013. Dissertação (Mestrado em História) - Instituto de Ciências Humanas e Filosofia, Universidade Federal Fluminense, Niterói, 2013.

VERGARA, M. Contexto e conceitos: história da ciência e vulgarização científica no Brasil do século XIX. Revista Interciência, v. 33, n. 5, p. 324-330, 2008. 


\section{Bibliografia complementar sobre o Museu Nacional}

ANDERMANN, J. Espetáculos da diferença: a Exposição Antropológica de 1882. Revista de História, Rio de Janeiro, v. 5, n. 9, p. 128-170, 2004.

ANDERMANN, J. The Museu Nacional at Rio de Janeiro. Relics and Selves: Articles. London: Birkbeck College (University of London), [s.d.]. Disponível em: http://www. bbk.ac.uk/ibamuseum/texts/Andermann01.htm\#top> Acesso em: 24 jun. 2018.

ANDRADE, A. de. O Museu Nacional e a difusão da Química. Rio de Janeiro: Tipografia do Museu Nacional, 1922.

AZEVEDO, F. (org.). As ciências no Brasil. Rio de Janeiro: Ed. UFRJ, 1994.

AZEVEDO, M. O Rio de Janeiro: sua história, monumentos, homens notáveis, usos e curiosidades. Rio de Janeiro: Garnier, 1877.

BENNETT, T. The birth of the museum: history, theory, politics. London: Routledge, 1995.

BITTENCOURT, J. N. Território largo e profundo: os acervos dos museus do Rio de Janeiro como representação do Estado Imperial, 1808-1889. 1997. Tese (Doutorado em História) - Universidade Federal Fluminense, Niterói, 1997.

CARNEIRO DA CUNHA, M. Política indigenista no século XIX. In: CARNEIRO DA CUNHA, M. (org.). História dos índios no Brasil. São Paulo: Companhia das Letras, 1998. p. 133-154.

CARVALHO, J. C. de M. Museu Nacional. Boletim do Conselho Federal de Cultura, Brasília, v. 7, jul./set. 1977.

CASTRO FARIA, L. As exposições de antropologia e arqueologia do Museu Nacional. Publicações Avulsas do Museu Nacional, Rio de Janeiro, v. 4, 1949.

CASTRO FARIA, L. Antropologia: espetáculo e excelência. Rio de Janeiro: Ed. UFRJ, 1993.

CASTRO FARIA, L. Antropologia: escritos exumados: espaços circunscritos: tempos soltos. Niterói: EDUFF, 1998.

CUNHA, D. F. A Biblioteca do Museu Nacional do Rio de Janeiro, 1863-1963. Rio de Janeiro: Museu Nacional, 1966.

DANTAS, R. M. M. C. O estudioso D. Pedro II, o imperador das novidades. In: GAZZANEO, L. M. C.; SARAIVA, S. B. C. (org.). A monarquia do Brasil: 1808-1889: reflexões sobre as artes e as ciências. Rio de Janeiro: Book Link, 2001. p. 167-177. 
DANTES, M. A. M. Institutos de pesquisa científica no Brasil. In: FERRI, M. G.; MOTOYAMA, S. (org.). História das ciências no Brasil. São Paulo: Edusp: CNPq: EPU, 1979-1980. v. 2, p. 341-380.

DOMINGUES, H. M. B. O Museu Nacional e o ensino das ciências naturais no Brasil no século XIX. Revista da Sociedade Brasileira de História da Ciência, v. 15, p. 79-87, 1996.

DOMINGUES, H. M. B.; SÁ, M. R. Controvérsias evolucionistas no Brasil do século XIX. In: DOMINGUES, H. M. B.; SÁ, M. R.; GLICK, T. (org.). A recepção do darwinismo no Brasil. Rio de Janeiro: Fiocruz, 2003. p. 97-124.

DUARTE, A. Ladislau Netto (1838-1894). Maceió: Imprensa Oficial, 1950.

DUARTE, L. F. D. Processos de classificação social nas coleções de um museu de ciências: o caso do Museu Nacional, Rio de Janeiro. In: SEMANA DOS MUSEUS DA UNIVERSIDADE DE SÃO PAULO, 2., 1999, São Paulo. Anais [...] São Paulo: Universidade de São Paulo, 1999.

DUARTE, L. F. D. Anthropologie, Psychanalyse et 'civilisation' du Brésil de l'entre-deux-guerres. Revue de Synthèse, v. 3-4, p. 325-344, juil./déc. 2000.

DUARTE, R. H. Em todos os lares, o conforto moral da ciência e da arte: a Revista Nacional de Educação e a divulgação científica no Brasil (1932-1934). História, Ciência, Saúde-Manguinhos, Rio de Janeiro, v. 11, n. 1, p. 33-56, jan./abr. 2004.

FIGUEIREDO, B. G.; VIDAL, D. G. (org.). Museus: dos gabinetes de curiosidades à museologia moderna. Belo Horizonte: Argumentum; Brasília: CNPq, 2005.

FUNDAÇÃO OSWALDO CRUZ. Casa de Oswaldo Cruz. Dicionário histórico-biográfico das ciências da saúde no Brasil (1832-1930). Disponível em: http://www.dichistoriasaude.coc.fiocruz.br. Acesso em: 23 fev. 2018.

GONÇALVES, J. R. S. Os museus e a representação do Brasil. Revista do Patrimônio Histórico e Artístico Nacional, v. 31, p. 254-273, 2005.

GUALTIERI, R. C. E. O evolucionismo na produção científica do Museu Nacional do Rio de Janeiro (1876-1915). In: DOMINGUES, H. M. B.; SÁ, M. R.; GLICK, T. (org.). A recepção do darwinismo no Brasil. Rio de Janeiro: Fiocruz, 2003. p. 45-96.

GUIMARÃES, M. L. S. Nação e civilização nos trópicos: o Instituto Histórico e Geográfico Brasileiro e o projeto de uma história nacional. Estudos Históricos, n. 1, p. 5-27, 1988.

HARTOG, F. et al. Entre as luzes e o romantismo: as tensões da escrita da história no Brasil oitocentista. In: GUIMARÃES, M. L. S. (org.). Estudos sobre a escrita da História. Rio de Janeiro: Sete Letras, 2006. p. 68-85. 
HEIZER, A. Os instrumentos científicos e as grandes exposições do século XIX. In: HEIZER, A.; VIDEIRA, A. A. P. (org.). Ciência, civilização e império nos trópicos. Rio de Janeiro: Access, 2001. p. 165-172.

HEIZER, A.; VIDEIRA, A. A. P. (org.). Ciência, civilização e império nos trópicos. Rio de Janeiro: Access, 2001.

IHERING, H. História do monumento do Ypiranga e do Museu Paulista. Revista do Museu Paulista, v. 1, p. 19-24, 1895.

KÖPTCKE, L. S. Bárbaros, escravos e civilizados: o público dos museus no Brasil. Revista do Patrimônio Histórico e Artístico Nacional, v. 31, p. 184-205, 2005.

KURY, L. Viajantes naturalistas no Brasil oitocentista: experiência, relato e imagem. História, Ciências, Saúde - Manguinhos, Rio de Janeiro, v. 8, supl., p. 863-880, 2001.

KURY, L. As artes da imitação nas viagens científicas do século XIX. In: ALMEIDA, M.; VERGARA, M. de R. (org.). Ciência, história e historiografia. São Paulo: Via Lettera; Rio de Janeiro: MAST, 2008. p. 321-333.

KURY, L. B. Comissão Científica do império. Rio de Janeiro: Andrea Jakobsson Estúdio, 2009.

LACERDA, J. B. Carta ao Sr. Dr. von Ihering, Director do Museo Paulista. Archivos do Museu Nacional, Rio de Janeiro, v. 9, p. 19-21, 1895.

LACERDA, J. B. Fastos do Museu Nacional do Rio de Janeiro: recordações historicas e scientificas fundadas em documentos authenticos e informações veridicas. Rio de Janeiro: Imprensa Nacional, 1906.

LACERDA, J. B.; PEIXOTO, R. Contribuições para o estudo anthropologico das raças indigenas do Brazil. Archivos do Museu Nacional, Rio de Janeiro, v. 1, p. 47-83, 1876.

LANGER, J. Ruínas e mito: a arqueologia no Brasil Império. 2000. Tese (Doutorado em História) - Universidade Federal do Paraná, Curitiba, 2000.

LEITÃO, C. de M. A Biologia no Brasil. São Paulo: Companhia Editora Nacional, 1937. (Biblioteca Pedagógica Brasileira [Coleção Brasiliana], série 5a , v. 99).

LOBO, B. (org.). O Museu Nacional de História Natural. Archivos do Museu Nacional, Rio de Janeiro, v. 22, p. 14-26, 1919.

LOPES, M. M. As ciências dos museus: a história natural, os viajantes europeus e as diferentes concepções de museus no Brasil do século XIX. In: ALFONSO-GOLDFARB, A. M.; MAIA, C. A. (org.). História da ciência: o mapa do conhecimento. Rio de Janeiro: Expressão e Cultura; São Paulo: Edusp, 1995. p. 721-732. 
LOPES, M. M. Viajando pelo mundo dos museus: diferentes olhares no processo de institucionalização das ciências naturais nos museus brasileiros. Imaginário, v. 3, p. 59-78, 1996.

LOPES, M. M. O Brasil descobre a pesquisa científica: os museus e as ciências naturais no século XIX. São Paulo: Hucitec, 1998.

LOPES, M. M. Nobles rivales: estudios comparados entre el Museo Nacional de Río de Janeiro y el Museo Público de Buenos Aires. In: MONTSSERAT, M. (org.). Nobles rivales: estudios comparados entre el Museo Nacional de Río de Janeiro y el Museo Público de Buenos Aires. Buenos Aires: Manantial, 2000. p. 277-296.

LOPES, M. M. O local musealizado em nacional - aspectos da cultura das ciências naturais no século XIX no Brasil. In: HEIZER, A.; VIDEIRA, A. A. P. (org.). Ciência, civilização e império nos trópicos. Rio de Janeiro: Access, 2002. p. 77-96.

MENDONÇA, E. S. de. A extensão cultural nos museus. Rio de Janeiro: Imprensa Nacional, 1946.

MOREIRA, I. de C.; MASSARANI, L.; ARANHA, J. Roquette-Pinto e a divulgação científica. In: LIMA, N. T.; SÁ, D. M. de (org.). Antropologia brasiliana: ciência e educação na obra de Edgar Roquette-Pinto. Belo Horizonte: UFMG; Rio de Janeiro: Fiocruz, 2008. p. 247-270.

MUSEU DE ASTRONOMIA E CIÊNCIAS AFINS (MAST). Conselho de Fiscalização das Expedições Artísticas e Científicas no Brasil: inventário sumário. Rio de Janeiro, 2000.

MUSEU DE ASTRONOMIA E CIÊNCIAS AFINS (MAST). Educação e museu: a construção social do caráter educativo dos museus de ciência. Rio de Janeiro, 2003.

NETTO, L. Prefacio. Archivos do Museu Nacional, Rio de Janeiro, v. 6, p. 1-5, 1885.

NETTO, L. Le Muséum National de Rio de Janeiro et son influence sur les sciences naturelles du Brésil. Paris: Charles Delagrave, 1889.

OITICICA FILHO, J. As publicações do Museu Nacional como contribuição para a ciência e a cultura. Publicações Avulsas do Museu Nacional, n. 42, 1961.

OLIVEIRA, J. T. de; VIDEIRA, A. A. P. As polêmicas entre Manoel Pereira Reis, Emmanuel Liais e Luiz Cruls na passagem do século XIX para o século XX. Revista da Sociedade Brasileira de História da Ciência, v. 1, p. 42-52, 2003. Disponível em: https://www. sbhc.org.br/revistahistoria/view?ID_REVISTA_HISTORIA=21. Acesso em: 15 ago. 2018.

RABELLO, A. et al. Uma leitura do acervo histórico-arqueológico do Museu Nacional. Rio de Janeiro: S. Mesquita e M. Beltrão, 2002. 
RIBEIRO, A. M. M. Heloisa Alberto Torres e Marina São Paulo de Vasconcelos: entrelaçamentos de círculos e formação das ciências sociais na cidade do Rio de Janeiro. 2000. Tese (Doutorado em Sociologia e Antropologia) - Instituto de Filosofia e Ciências Sociais, Universidade Federal do Rio de Janeiro, Rio de Janeiro, 2000.

ROMERO, S. Ethnographia brazileira: estudos criticos sobre Couto de Magalhães, Barbosa Rodrigues, Theophilo Braga e Ladislau Netto. Rio de Janeiro: Livraria Clássica de Alves \& Cia., 1888.

SÁ, M. R. O botânico e o mecenas: João Barbosa Rodrigues e a ciência no Brasil na segunda metade do século XIX. História, Ciência, Saúde-Manguinhos, Rio de Janeiro, v. 3, p. 899-924, 2001.

SALLES, R. Nostalgia imperial: a formação da identidade nacional no Brasil do Segundo Reinado. Rio de Janeiro: Topbooks, 1996.

SANJAD, N. A Coruja de Minerva: o Museu Paraense entre o Império e a República (1866-1907). Brasília: Instituto Brasileiro de Museus; Belém: Museu Paraense Emílio Goeldi; Rio de Janeiro: Fundação Oswaldo Cruz, 2010.

SCHWARCZ, L. M. O espetáculo das raças: cientistas, instituições e questão racial no Brasil, 1870-1930. São Paulo: Companhia das Letras, 1993.

SCHWARCZ, L. M. As barbas do imperador: D. Pedro II, um monarca nos trópicos. São Paulo: Companhia das Letras, 1998.

SCHWARTZMAN, S. Formação da comunidade científica no Brasil. São Paulo: Nacional; Rio de Janeiro: Finep, 1979.

SOARES, M. C.; AGOSTINHO, M. B.; LIMA, R. C. Conhecendo a exposição Kumbukumbu do Museu Nacional. Rio de Janeiro: Museu Nacional, Universidade Federal do Rio de Janeiro, 2016. (Série Livros Digital 4).

SOUZA LIMA, A. C. Os museus de história natural e a construção do indigenismo. Comunicações do PPGAS, Rio de Janeiro, v. 13, 1989.

TREECE, D. Victims, allies, rebels: towards a new history of nineteenth-century Indianism in Brazil. Portuguese Studies, v. 2, p. 56-98, 1986.

TURAZZI, M. I. Poses e trejeitos: a fotografia e as exposições na era do espetáculo (1839-1889). Rio de Janeiro: Funarte: Rocco, 1995.

Recebido: 29/11/2018 Aceito:30/11/2018 | Received: 11/29/2018Accepted: 11/30/2018 